\title{
Treatment of glycerol phase formed by biodiesel production
}

Martin Hájek*, František Skopal

\section{All authors:}

Department of Physical Chemistry, Faculty of Chemical Technology, University of Pardubice, Pardubice, Czech Republic

\section{Postal address:}

Martin Hájek, Department of Physical Chemistry, Faculty of Chemical Technology, University of Pardubice, Studentská 573, 53210 Pardubice, Czech Republic.

Phone: +420 466037 055, Fax: +420 466037 068;

e-mail: martin.hajek2@upce.cz

Keywords: glycerol, biodiesel, transesterification, saponification, higher fatty acids

* corresponding author 


\begin{abstract}
Glycerol is a by-product of biodiesel produced by transesterification and is contained in the glycerol phase together with many other materials such as soaps, remaining catalyst, water, and esters formed during the process. The content of glycerol is approximately 30-60 wt.\%. In this paper, treatments of the glycerol phase to obtain glycerol with a purity of $86 \mathrm{wt} . \%$ (without distillation) and a mixture of fatty acids with esters (1:1) or only a mixture of fatty acids with a purity of $99 \mathrm{wt} \%$ are presented. The treatment was carried out by removing of alkaline substances and esters. Fatty acids were produced by saponification of the remaining esters and subsequent neutralization of alkaline substances by phosphoric, sulfuric, hydrochloric or acetic acids. Salts are by-products and, in the case of phosphoric acid can be used as potash-phosphate fertilizer. The process of treatment is easy and environmentally friendly, because no special chemicals or equipment are required and all products are utilizable.
\end{abstract}

\title{
1 Introduction
}

Glycerol is a trivalent alcohol widely used in the pharmaceutical, food, cosmetic and chemical industries. It is produced from soaps which are obtained by saponification of triglycerides from vegetable oils or animal fats. During their saponification, triglycerides are converted by alkaline hydroxides into salts of fatty acids (soaps) and glycerol (Zajíc, 1988). Glycerol can also be produced from propene (Cervinka, 1991). Another possibility to gain glycerol is through transesterification of vegetable oils and animal fats. In the EU, the production of biodiesel was 7.56 million tons in 2008 (EBB, 2009). Approximately one fifth of this amount is glycerol.

During biodiesel production, two phases are produced after transesterification and distillation of the excess alcohol. The upper ester phase (EP) contains the main product - biodiesel. The lower glycerol phase (GP) consists of glycerol and many other chemical substances such as water, organic and inorganic salts, a small amount of esters and alcohol, traces of glycerides and vegetable colors. The exact composition of the raw GP depends on the method of 
transesterification and the separation conditions of biodiesel production, but the glycerol concentration is usually between 30 and 60 wt.\%.

The crude glycerol phase can be purified by ion exchange on the strong acid resin Amberlite252 and it has been suggested that the macroporous Amberlite could be useful for removal of sodium ions from glycerol/water solutions with a high salt concentration (Carmona et al., 2008). Another technology of purification of glycerol with high salt content is by ion-exchange Ambersep BD50 (Lancrenon et al., 2008). Many purification methods are based on the distillation of the glycerol phase to strip alcohol contaminants from glycerol (Potthast et al., 2009) or the Rototherm ${ }^{\circledR}$ mechanically-agitated thin film processor to continuously evaporate and distill glycerol and other heat sensitive solids-containing products (Ramtox et al., 2007). Glycerol can also be recovered by heating a glycerol-containing effluent stream containing a low molecular weight alcohol, water and fatty acid esters (Aiken, 2006). The reaction mixture is sparged with nitrogen to help remove water and low molecular weight alcohol.

Glycerol gained from the biodiesel production can be used for a variety of processes such as for docosahexaenoic acid fermentation by the microalga Schizochytrium limacinum (Zhanyou et al., 2007), for the transformation to 1,3-propandiol by immobilized Gluconobacter oxydans (Raška et al., 2007), the chemical conversion to 1,2-propandiol (Dasari et al., 2005), etherification with isobutene (Karinen et al., 2006), for syngas production (Valliyappan et al., 2008), and utilization in automotive fuel (Fernando et al., 2007).

For utilizations, it is important to gain glycerol in a more concentrated form with minimum amount of other chemical substances because these substances complicate further utilization of glycerol. The utilization of the by-product of biodiesel production would significantly improve the economic aspect of overall biodiesel production.

In our technology of biodiesel production, the transesterification by methanol (methanolysis) is catalyzed by potassium hydroxide. The methanolysis is stopped by neutralization of the catalyst by gaseous carbon dioxide, which ensures that the acid number of formed biodiesel fills 
the norm (less than $0.2 \mathrm{mgKOH} / \mathrm{g}$ ). Carbon dioxide behaves as a weak acid and therefore cannot transform soaps (formed by side reaction - saponification) to fatty acids (which increase the acid number). The formed potassium carbonate and bicarbonate have no catalytical effect (Skopal et al., 2001). Reaction mixture is gravitatively separated into the EP and the GP after distillation off of methanol (from the total reaction mixture - EP and GP). It is important to gain the single components (glycerol, fatty acids and other materials) from the GP in a more usable form.

\section{Methods}

\subsection{Chemicals}

The raw glycerol phase with different compositions (Tab. 1), potassium hydroxide pure (83 wt\% purity), methanol (technical grade), sulphuric acid (96 wt.\%), hydrochloric acid (36 wt.\%), phosphoric acid p.a. (85 wt.\%), and acetic acid, were purchased from Lach-Ner, Czech Republic. Deionized water was used for the experiments.

\subsection{Experimental procedure}

\subsubsection{Neutralization}

The principle of the GP purification consists in neutralization of alkali substances by strong acid (see 3.1). Five-hundred g of the glycerol phase was placed in a 1-L batch glass reactor and diluted with $130 \mathrm{~g}$ of methanol. Concentrated phosphoric acid was slowly added until a pH of 3 - 4 was reached and the mixture was stirred for 15 min. Precipitated salt was removed by filtration through a frit type S1 (porus size $110 \mu \mathrm{m}$ ) and the excess of methanol was distilled off at $60^{\circ} \mathrm{C}$, a pressure of $3 \mathrm{kPa}$ over a 50 -min period. Then, the heterogeneous reaction mixture was cooled to $25^{\circ} \mathrm{C}$ and poured into a separation funnel. After complete separation, the upper organic phase (OP) was analyzed for the acid number and esters and the lower concentrated GP was analyzed for the amount of glycerol, acids, salts and water. Three samples of the raw 
glycerol phase with different compositions were tested (Tab. 1), using four acids (phosphoric, sulfuric, hydrochloric and acetic). The process for every acid was repeated four times.

\subsubsection{Saponification}

The saponification of remainder esters by strong alkali chemicals is another possibility of treatment. Five-hundred g of raw GP was place into a 1-L batch glass reactor and thermostated to $25{ }^{\circ} \mathrm{C}$. Solid potassium hydroxide was dissolved in methanol and added under stirring to the reactor to start saponification of the esters. The amount of $\mathrm{KOH}$ was calculated with respect to known amount of esters in the GP and it is expressed by molar ratio of $\mathrm{KOH}$ to ester (first column in Tables 5 and 6). After $60 \mathrm{~min}$, the reaction mixture was neutralized with concentrated phosphoric acid. The procedure was continued with neutralization, as described in section 2.2.1. The diagram of the procedure is depicted in Fig. 1.

\subsection{Analytical methods}

The yields of phases were defined and determined as the weight ratios of the phase to the raw glycerol phase. The yield of formed precipitate (in wt.\%) was calculated as the weight ratio of the experimentally determined measurement and a theoretic calculated value (from the known composition of the raw GP) multiplied by 100. The density of the OP was determined by pycnometer.

The determination of the acid value in the OP was carried out by alkalimetric titration with an ethanolic solution of $\mathrm{KOH}(0.1 \mathrm{~mol} / \mathrm{l})$ with visual detection of the equivalence point as described in EN 14214.

The determination of dissolved traces of $\mathrm{H}_{3} \mathrm{PO}_{4}$ and $\mathrm{KH}_{2} \mathrm{PO}_{4}$ in the CGP was carried out by one alkalimetric titration with potassium hydroxide $(0.1 \mathrm{~mol} / \mathrm{l})$ in water. A couple of electrodes (glass - saturated silver chloride) was used as detector. The result of this determination was a two-step titrimetric curve, where both equivalence points were evaluated by second-order derivation. 
The mass fractions of the potassium carbonate, potassium hydrogen carbonate and soaps in the GP were determined by acidimetric titration. For a calculation of the amount of soaps and potassium hydrogen carbonate, it was necessary to determine the volume of escaped carbon dioxide from the GP after acidification as described by (Kwiecien et al., 2009).

Glycerol was determined in both phases by iodometric titration (Jurecek, 1957). The water content was determined by volumetric Karl Fischer titration with biamperometric end-point indication using an automatic titrator 736 GP Titrino®, Metrohm. Methanol and esters were determined by GC with FID detection as described by Komers et al. (1998).

\section{Results and discussion}

\subsection{Principle of treatment}

The addition of strong acid - neutralization - transforms the soaps (present in the GP from the saponification of oil during biodiesel production) into free higher fatty acids and inorganic salt (1), carbonates into carbon dioxide and inorganic salt (2). In the following equation, $\mathrm{R}$ is hydrophobic rest of fatty acids.

$$
\begin{aligned}
& \text { Neutralization of soaps: R-COOK }+\mathrm{H}^{+} \longrightarrow \mathrm{R}-\mathrm{COOH}+\mathrm{K}^{+} \\
& \text {Carbonates acidification: } \mathrm{K}_{2} \mathrm{CO}_{3}+\mathrm{KHCO}_{3}+3 \mathrm{H}^{+} \longrightarrow 3 \mathrm{~K}^{+}+2 \mathrm{CO}_{2}+2 \mathrm{H}_{2} \mathrm{O}
\end{aligned}
$$

Other possibility of treatment of the GP is a previous saponification of the remaining esters by strong alkali material to soaps in the first step (3), and then, the neutralization step.

$$
\text { Saponification of esters: R-COOCH}{ }_{3}+\mathrm{OH}^{-} \longrightarrow \mathrm{R}-\mathrm{COO}^{-}+\mathrm{CH}_{3} \mathrm{OH}
$$

Then, the GP is gravitatively separated to two phases: a lighter (upper) phase containing organic substances (fatty acids and esters) called the organic phase - OP and a heavier (bottom) phase containing polar substances (glycerol, water and inorganic salts), called as the concentrated glycerol phase - CGP. 


\subsection{Purification without saponification}

The neutralization of alkali materials on the GP was carried out with three strong concentrated inorganic acids (sulphuric, hydrochloric and phosphoric) and one organic acid (acetic acid).

The concentrated glycerol phase contains on average approximately $84 \mathrm{wt} \%$ of glycerol, 12 wt.\% of water and minimal amounts, after neutralization, of acid and salt. The exact composition (including precipitate yield) is stated in Tab. 2. The organic phase contains a mixture of esters and high fatty acids (Tab. 3) and its composition is almost the same regardless the type of the used inorganic acids: the weight ratio of esters and higher fatty acids is 1:1.

The precipitate, which can be filtered off, was formed when inorganic acids were used. The potassium acetate remained dissolved in the reaction mixture. The formed precipitates of salts of sulphuric and hydrochloric acid were very difficult to filter and filtration took a long time (2 - 3 hours). The easy filterable crystallic precipitate was formed only when phosphoric acid was used for neutralization (filtration took about $10 \mathrm{~min}$ ). After the removal of methanol, the separation of phases was took only about $30 \mathrm{~min}$ for the $\mathrm{H}_{3} \mathrm{PO}_{4}$-treated, but $3 \mathrm{~h}$ for the $\mathrm{HCl}$ - and $10 \mathrm{~h}$ for the $\mathrm{H}_{2} \mathrm{SO}_{4}$ - and $\mathrm{CH}_{3} \mathrm{COOH}$-treated samples. The next advantage of phosphoric acid is that phosphorus is a biogenous element and thus potassium dihydrogenphosphates (contain $28 \%$ of potassium and $20 \%$ of phosphorus) can be used as fertilizer without further purification. A comparison of the outcomes for the different acids used is provided in Tab. 4.

The effect of methanol amount (calculated as weight ratio of methanol to raw GP) on the yield of the formed precipitate $\left(\mathrm{KH}_{2} \mathrm{PO}_{4}\right)$ is depicted in Fig. 2. The yield of precipitate was increasing with increasing amount of methanol, because $\mathrm{KH}_{2} \mathrm{PO}_{4}$ is insoluble in methanol. Therefore it is better to use a higher amount of methanol for dilution of the GP (about 2630 wt.\%).

The distilled methanol can be used again for the dilution of the further raw GP, but it is necessary to decrease the content of water to less than $1 \%$. 


\subsection{Purification with saponification}

The OP contains approximately 50 wt.\% of esters. In order to obtain free fatty acids only, the esters in the GP were saponified with potassium hydroxide prior to neutralization at a molar ratio of $\mathrm{KOH}$ to esters of 1:1.

After saponification and neutralization, the concentration of glycerol in the CGP was approximately 84 wt.\% and the rest was mainly water (no esters). The OP contained 95 wt.\% of free fatty acids and a small amount of esters, because the saponification did not proceed to completion. Therefore, in the next experiments the molar ratio of $\mathrm{KOH}$ to ester was increased to 1.2:1. The composition of the CGP was almost the same, but the OP contained only a mixture of higher fatty acids and no esters.

The results of the analyses for both $\mathrm{KOH}$ :ester molar rations are presented in Table 5 for the concentrated glycerol phase and in Table 6 for the organic phase.

The advantages of this treatment of the GP are that the expensive distillation of glycerol is not needed, the main impurity in the CGP is water and, in the case of usage of phosphoric acid, the by-product is usable fertilizer. It is possible to prepare a mixture of higher fatty acids and removal of alkali substances from the GP by this process.

\section{Conclusions}

Glycerol with a purity of approximately $86 \mathrm{wt} \%$ and a mixture of esters and free fatty acids (via neutralization) or only free fatty acids with a purity of $99 \mathrm{wt} \%$ (via saponification plus neutralization) was achieved. Neutralization of soaps to free fatty acids and carbonates to carbon dioxide was accomplished with concentrated phosphoric acid. The by-product of neutralization is the potash-phosphate fertilizer $\left(\mathrm{KH}_{2} \mathrm{PO}_{4}\right)$. The process of treatment is easy and relatively environmentally friendly. 


\section{Acknowledgements}

This work has been funded by the research project MSM 0021627502 of the Czech Ministry of Education, Youth and Sport.

\section{References}

Aiken, J.,2006. Purification of glycerin. United States Patent 7126032

Carmona, M., Valverde, J., Pérez, A., 2008. Purification of glycerol/water solutions from biodiesel synthesis by ion exchange: sodium removal Part I. Journal of Chemical Technology \& Biotechnology 84, 738-744.

Červinka, O., Dědek, V., 1980. Organická chemie, second ed. Státní nakladatelství technické literatury, Praha

Dasari, M., Kiatsimkul, P., Sutterlin, W., 2005. Low-pressure hydrogenolysis of glycerol to propylene glycol. Applied Catalysis A: General. 281, 225-231.

EBB: European Biodiesel Board, 2009. http://www.ebb-eu.org/stats.php

Fernando, S., Adhikari, S., Kota K., Bandi, R., 2007. Glycerol based automotive fuels from future biorefineries. Fuel. 86, 2806-2809.

Jurecek M.: Organická analysa II. CSAV Praha 1957.

Karinen, R.S., Krause, A.O.I., 2006. New biocomponents from glycerol. Applied Catalysis A: General. 306, 128-133. 
Komers, K., Stloukal, R., Machek, J., 1998. Biodiesel fuel from rapeseed oil, methanol, and KOH. Analytical methods in research and production. Fett/Lipid. 100, 507-512.

Kwiecien, J., Hájek, M., Skopal, F., 2009. The effect of the acidity of rapeseed oil on its transesterification. Bioresour. Technol. 100, 5555-5559.

Potthast, R., Chung, C., Mathur I., 2009. Purification of glycerin obtained as a bioproduct from the transesterification of triglycerides in the synthesis of biofuel. United States Patent AC07C2980FI

Lancrenon, X., Fedders, J., 2008. An Innovation in Glycerin Purification. Biodiesel magazin June 2008

Ramtox Corporation, 2008. Glycerin purification and recovery system. Ramtox Corporation Newsletter 1, 1-2. http://www.ramtox.com/html/biofuel.html

Raška, J., Skopal, F., Komers, K., Machek, J., 2007. Kinetics of glycerol biotransformation to dihydroxyacetone by immobilized Gluconobacter oxydans and effect of reaction conditions. Collect. Czech. Chem. Commun. 72, 1269 - 1283.

Skopal, F., Komers, K., Machek, J., Koropecký, I., 2001. Způsob výroby bionafty z rostlinných olejů, zejména z řepkového oleje. Czech patent CZ 289417.

Valliyappan, T., Bakhshi, N.N., Dalai, A.K. 2008. Pyrolysis of glycerol for the production of hydrogen or syn gas. Bioresour. Technol. 99, 4476-4483.

Zajíc, J. 1988. Chemie a technologie tuků, VŠCHT, Praha 
Zhanyou Chi, Denver, P., Zhiyou, W., Craig, F., 2007. A laboratory study of producing docosahexaenoic acid from biodiesel-waste glycerol by microalgal fermentation. Process Biochem. 42, 1537-1545. 


\section{Figure captions:}

Fig 1: Diagram of saponification and neutralization procedure

Fig 2: Dependence of precipitate yield on amount of methanol used 